Eur. J. Clin. Chem. Clin. Biochem.

Vol. 31, 1993, pp. 695-699

(C) 1993 Walter de Gruyter \& Co.

Berlin - New York

\title{
A Rapid Field Test for the Determination of Colostral Ingestion by Calves, Based on $\gamma$-Glutamyltransferase
}

\author{
By E. Bogin, Y. Avidar, S. Shenkler, Bat-Ami Israeli, N. Spiegel and R. Cohen \\ Kimron Veterinary Institute and Koret School of Veterinary Medicine, Bet-Dagan, Israel
}

(Received December 12, 1990/June 17, 1993)

\begin{abstract}
Summary: A qualitative field test for determining the blood level of the enzyme $\gamma$-glutamyltransferase is described for the evaluation of colostral ingestion. The method for enzyme determination is based on dry chemistry technology, and a simple $37^{\circ} \mathrm{C}$ incubator and colour chart for estimating the activity. There were good correlations between results obtained with the field tests and those obtained with the Reflotron ${ }^{\circledR}$ and the wet chemistry conventional methods. Following colostral intake by the calf, blood $\gamma$-glutamyltransferase increased more than 100 fold. There were good correlations between $\gamma$-glutamyltransferase and total globulins in the serum on days 2 and 3 after colostrum intake. Lower but significant correlations were seen between the enzyme and serum total proteins. Good correlation was also seen between the serum enzyme activity and the albumin to globulin ratio. Electrophoretic separation of calf serum showed a significant increase of $\gamma$ globulins after colostral ingestion. The implications and importance of field test are discussed.
\end{abstract}

\section{Introduction}

The problem of diarrhoea in neonatal calves is very widespread and accounts for a large percentage of the total losses in the cattle industry. Prevention of neonatal calf diarrhoe in the herd depends to a large extent on lactogenic immunity obtained by ingestion of colostral immunoglobulins $(1,2)$. The importance of colostrum to newborn calf survival has been shown to be related to the protection given by immunoglobulins in the colostrum $(3-5)$.

Calves, like most domestic animals, are born lacking circulating immunoglobulin and therefore must absorb maternal immunoglobulin from colostrum for passive immunity during the neonatal period.

Often, the occurrence of diarrhoeal diseases of neonatal calves is linked to low serum immunoglobulin concentrations, which in turn is frequently related to insufficient colostral ingestion. The colostral immunoglobulin concentration, and the volume of colostrum ingested determines the quantity of immunoglobulin present in the blood of the calf. The ability of the newborn calf to absorb colostral immunoglobulin decreases quite rapidly following birth and essentially stops by about 24 hours of age $(1-7)$. Naturally suckled calves ingest an average of 2 litres or more of colostrum. However, individual dairy calves, even those seen actively suckling, rarely ingest adequate amounts of colostrum. It has been reported that $25-$ $34 \%$ of calves fail to suckle by $6-8$ hours of age ( 2 , $5-7)$.

Impaired immunoglobulin absorption by calves can result from a delay in suckling and/or poor suckling drive of the calf, poor mothering behaviour of the dams, or other factors $(1-3,5,6,8,9)$. Early detection prior to the closure (decreased absorption) in the immunoglobulin-deficient calves is of great importance, because it can enable supplementation with colostrum and correction of the immunoglobulin deficiency.

Several tests for the evaluation of colostral ingestion are available. The tests can be divided into two main groups: 
(a) Accurate tests for immunoglobulin, which do not provide a rapid result. For these methods, blood samples have to be shipped to, and analysed in, the laboratory and require special professional training and equipment.

(b) Tests which can be done in a relatively short time on the farm and under "field" conditions, and do not require much training or equipment. These tests however are qualitative in nature and are not accurate. This group include the glutaraldehyde test, the zinc sulphate turbidity test and the determination of total proteins by refractometry.

All the above tests require a centrifuge for separation of serum or plasma.

The value of $\gamma$-glutamyltransferase as a marker for colostral intake has been previously investigated $(10$, 11). Boyd (12) used a computer simulation to show the pattern of this enzyme and of globulins in calf serum following colostral intake. Braun et al. (11) concluded that $\gamma$-glutamyltransferase can serve as a marker for colostral intake.

We describe a rapid test using dry chemistry technology for the estimation of colostral ingestion by the calf, working with either whole blood or serum. The test can be performed on the farm, quantitatively using an analyser, or qualitatively using a colour chart.

\section{Materials and Methods}

Blood was taken from the jugular vein of calves before and at different times after calving and colostral ingestion. Either whole blood or serum were analysed for serum $\gamma$-glutamyltransferase and proteins.

$\gamma$-Glutamyltransferase (EC 2.3.2.2) was determined using three procedures:

(a) The "Kone" autoanalyser continuous method with $L$-glutamyl p-nitroanilide and glycylglycine;

(b) Boehringer-Mannheim dry chemistry system with the Reflotron $^{\oplus}$, using $\gamma$-glutamyl-3-carboxy-1,4 phenylene diamine and glycylglycine;

(c) A qualitative test developed for field conditions.

Total serum proteins were determined by the colorimetric method using the biuret reagent (13). Albumin was determined colorimetrically using the bromocresol green reagent (14). Serum total globulin concentrations were calculated by subtracting albumin from total proteins.

$\gamma$-Glutamyltransferase was determined under field conditions by using the Boehringer-Mannheim Reflotron ${ }^{(1)}$ dry chemistry enzyme strip (15). Following the application of $32 \mu \mathrm{l}$ whole blood or serum, the strip was incubated in a specially developed, battery operated incubator adjusted to $37 \pm 1{ }^{\circ} \mathrm{C}$. At the end of 120 seconds, the intensity of the formed blue colour was compared with a colour chart representing enzyme activities up to $1000 \mathrm{U} / 1$. As an additional means of maintaining a temperature of $37^{\circ} \mathrm{C}$, the strip was placed in a test tube and kept under the armpit, once again comparing the formed colour against the colour chart (fig. 1). The enzyme was also determined with Boehringer-Mannheim's Reflotron ${ }^{\otimes}$ in the laboratory or on the farm using dry chemistry strips (15) and with the "Kone" autoanalyser using the continuous colorimetric method at $37^{\circ} \mathrm{C}(16,17)$. The same serum was analysed with all three methods at $37^{\circ} \mathrm{C}$, the results were compared and the correlation was determined.

Electrophoresis of serum proteins and colostrum was performed with the Helena Laboratories Titan Gel Kit (Texas, USA). Identification and quantitation were done with a Cliniscan 2 (Helena Lab. USA).

\section{Results}

The serum concentrations of $\gamma$-glutamyltransferase, total proteins, albumin and globulins before and at different times after calving are given in table 1 and figure 2 . There were significant increases of $\gamma$-glut-

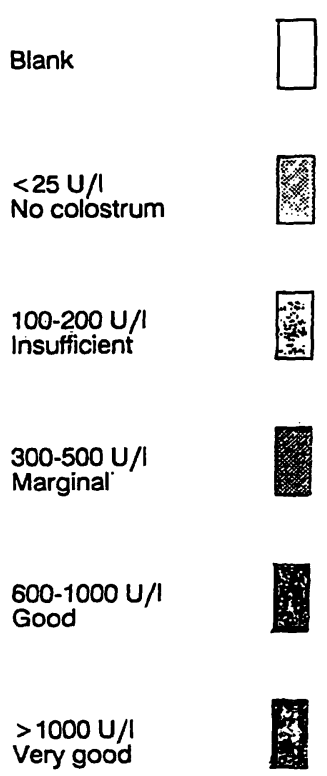

Fig. 1. Colour chart for the qualitative determination of the activity of serum $\gamma$-glutamyltransferase

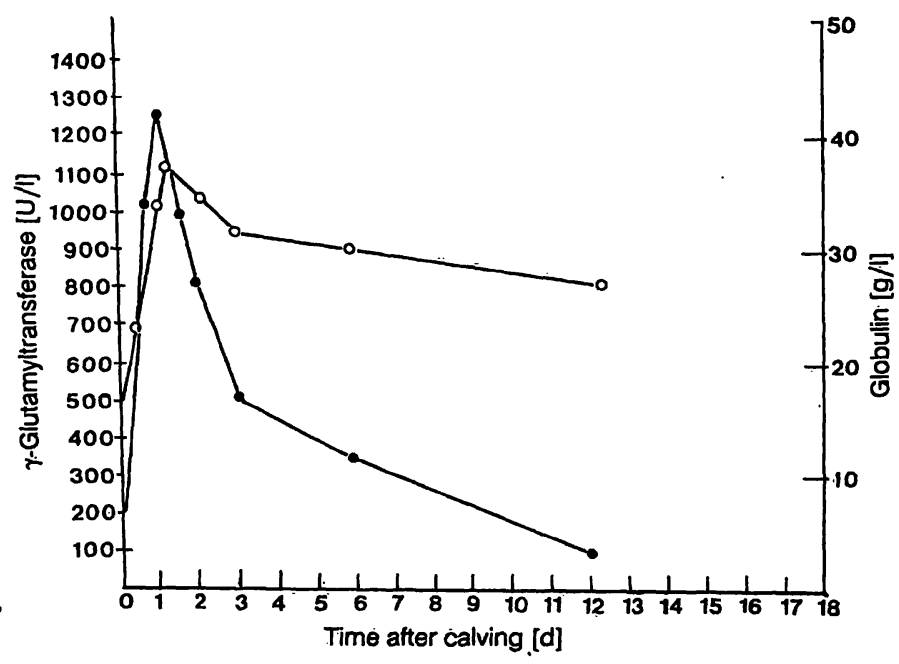

Fig. 2. Blood activities of colostrai ${ }^{\prime} \gamma$-glutamyltransferase and concentrations of globulins in calves at different times after calving 
Tab. 1. Activity of serum $\gamma$-glutamyltransferase, concentrations of total protein, albumin, globulins and albumin to globulin ratio, before and after colostral intake

Time after colostral intake

Quantity

(days)

$\gamma$-Glutamyltransferase

$(\mathrm{U} / \mathrm{l})$

\begin{tabular}{ll} 
& n \\
\hline Before & 18 \\
1 & 13 \\
2 & 11 \\
3 & 12 \\
$4-8$ & 11 \\
$11-14$ & 15 \\
\hline
\end{tabular}

Total protein

(g/l)
Albumin
(g/l)

Quantitative Qualitative

$\begin{array}{rlcl}13.1 \pm & \pm .2 & <25 & 45.6 \pm 2.8 \\ 1481 & \pm 1180 & >1000 & 61.6 \pm 8.5 \\ 876 & \pm 816 & 600-1000 & 62.5 \pm 8.3 \\ 508 \pm \pm 549 & 500-600 & 61.3 \pm 7.0 \\ 355 \pm 242 & 400 & 55.9 \pm 5.6 \\ 72 \pm 59 & 100 & 55.6 \pm 6.7\end{array}$

$31.5 \pm 2.4$
$27.7 \pm 3.9$
$28.5 \pm 2.3$
$27.8 \pm 2.3$
$27.8 \pm 3.2$
$28.6 \pm 2.2$

Globulin

(g/l)
Albumin

Globulin

$\overline{\mathrm{x}} \pm \mathrm{SD}$

* estimation by the colour chart

amyltransferase in calf serum following colostral ingestion, from a mean level of $13.1 \mathrm{U} / 1$ before ingestion to $1481 \mathrm{U} / 1$ one day after ingestion. There was a gradual decrease of the enzyme activity with time, reaching a mean level of $72 \mathrm{U} / \mathrm{l}$ at $11-14$ days after colostral ingestion. Measurement of serum proteins before and after colostral ingestion showed that the largest relative increase occurred in total globulin (from a mean of 14.0 to $33.9 \mathrm{~g} / 1$ - an increase of $142 \%$ ). The relative increase in the serum concentrations of total proteins was only $35 \%$, which is much smaller than that seen for globulins. There was no significant change in serum albumin concentration, but the albumin to globulin ratio changed significantly from 2.25 prior to colostral ingestion, to 0.82 one day later, gradually increasing to 1.06 two weeks later.

The clearance rate of $\gamma$-glutamyltransferase, as evaluated by the half life, is biphasic. The first phase is about 42 hours, the second about 7 days.

Table 2 shows the correlation between $\gamma$-glutamyltransferase and serum protein concentrations. There were good and significant correlations between $\gamma$ glutamyltransferase and serum globulin, with the highest value (0.93) on day 3 . Lower but significant correlations were seen on days 1 and 2. A low but significant correlation was seen between $\gamma$-glutamyltransferase and total serum proteins on days 2 and 3.

The electrophoretic pattern of calf serum before and after colostral ingestion is shown in figure 3 (a representative example). It can be seen that prior to colostral ingestion the concentrations of total serum proteins were significantly lower, with only residual amounts of $\gamma$-globulins and low activity of $\gamma$-glutamyltransferase. Following colostral ingestion, total serum proteins increased (from 41.0 to $63.0 \mathrm{~g} / \mathrm{l}$ ), $\gamma$ glutamyltransferase activity increased (from 21.1 to $2845 \mathrm{U} / \mathrm{l})$ and $\gamma$-globulins from less than $5 \%$ to $23 \%$ of the total serum proteins.

Tab. 2. Correlation coefficients and degree of significance between $\gamma$-glutamyltransferase and total proteins, albumin and globulin

\begin{tabular}{llll}
\hline $\begin{array}{l}\text { Time after } \\
\text { colostral } \\
\text { intake } \\
\text { (days) }\end{array}$ & $\begin{array}{l}\text { Total } \\
\text { protein }\end{array}$ & Albumin & Globulin \\
\hline Before & $0.17 ; 0.5$ & $0.018 ; 0.94$ & $0.14 ; 0.58$ \\
1 & $0.55 ; 0.10$ & $0.4 ; 0.25$ & $0.71 ; 0.02$ \\
2 & $0.75 ; 0.0001 \cdot$ & $0.07 ; 0.05$ & $0.82 ; 0.001$ \\
3 & $0.74 ; 0.01$ & $0.07 ; 0.84$ & $0.93 ; 0.003$ \\
$4-8$ & $0.19 ; 0.62$ & $0.56 ; 0.11$ & $0.6 ; 0.08$ \\
$11-14$ & $0.48 ; 0.07$ & $0.23 ; 0.41$ & $0.53 ; 0.04$ \\
\hline
\end{tabular}

$\mathrm{n}=11-18$

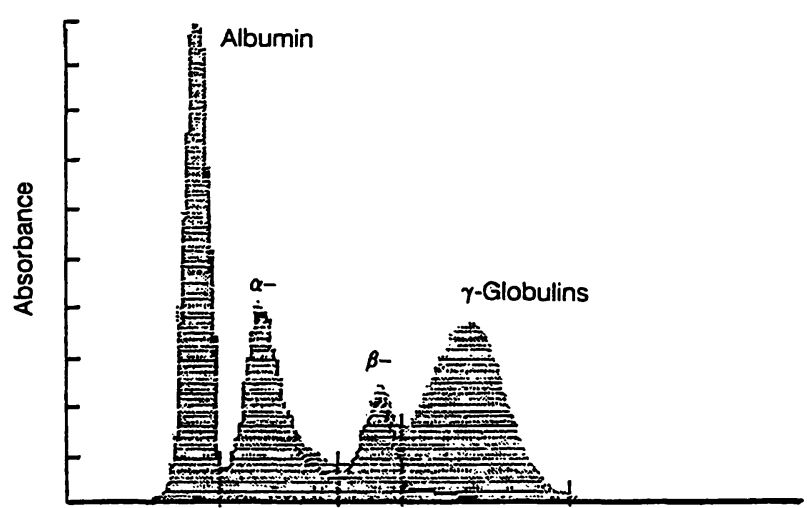

Fig. 3. Calf serum electrophoresis before and after colostral ingestion

$\begin{array}{lc}\text { Before colostral ingestion (dark line) } & \\ \quad \text { total proteins }(\mathrm{g} / \mathrm{l}) & 41.0 \\ \gamma \text {-glutamyltransferase (U/l) } & 21.1 \\ & \\ \text { After colostral ingestion (gray line) } & \\ \quad \text { total proteins (g/l) } & 63.0 \\ \gamma \text {-glutamyltransferase (U/l) } & 2845\end{array}$


The protein fractions in the colostrum are shown in figure 4; the major fraction was $\gamma$-globulin.

Correlation coefficients for two variables from calving until 2 weeks later were: serum total protein against globulins $0.9956 ; \gamma$-glutamyltransferase vs albumin to globulin ratio at $0-14$ days -0.6061 , at $1-14$ days -0.9379 .

\section{Discussion}

A method for the determination of colostral ingestion is described. Although not showing the quantity of specific immunoglobulins, it indirectly indicates the amount and possibly the quantity of the colostrum ingested.

The fact that the test can be performed under field conditions by the practitioner or the farmer is advantageous, since it can serve for the early evaluation of colostral ingestion, leaving time for any necessary corrective measures, before the absorption of proteins into the blood ceases.

It seems that $\gamma$-glutamyltransferase is a satisfactory marker of colostral ingestion since:

(a) its activities in normal healthy animals are low (up to $25 \mathrm{U} / \mathrm{l}$ ) compared with values seen in calves following colostral ingestion (over $1000 \mathrm{U} / 1$ );

(b) the enzyme activity in the colostrum is very high;

(c) the enzyme is absorbed into the blood in parallel with the immunoglobulins;

(d) the enzyme determination is simple and inexpensive, and available as a dry chemistry system.

Although the laboratory evaluation of serum proteins and particularly immunoglobulins is more precise, samples must first be transported to the laboratory, then processed and analysed, so that the result is often

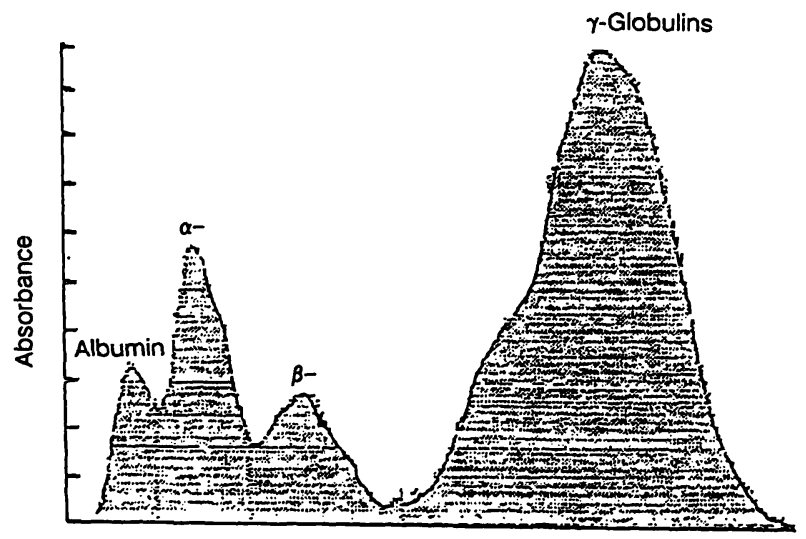

Fig. 4. Electrophoretic separation of cows' colostrum produced after the "critical time", when it is too late for corrective measures. Moreover, such methods require sophisticated and expensive equipment and qualified trained personnel. It is therefore of great diagnostic value to perform the test near the animal, producing an immediate answer, and allowing a better diagnosis and immediate treatment. It is preferable to have a test result which is fast, even though it is qualitative in nature.

The developed field test for evaluating colostral intake is based on this concept. It is fast, inexpensive, does not require sophisticated equipment and can be performed by the practitioner or farmer near the animal and under field conditions.

At present several qualitative field tests exist for the evaluation of colostral intake. They include the glutaraldehyte test and the zinc sulphate turbidity test for determining the immunoglobulin concentrations and the determination of serum total proteins by refractometry. All these methods require serum or plasma, which means that a centrifuge is needed, something which is not available under field conditions.

The proposed method, based on existing technology of Boehringer-Mannheim's Reflotron ${ }^{\circledR}$, was adapted for operation under field conditions, utilizing the fact that the test can be operated with whole blood without centrifugation. The development of the method was also facilitated by the fact that a distinct colour is formed, which can be evaluated by comparison with a colour chart, each colour corresponding to a particular level of activity.

The development of dry chemistry technology made it possible to convert many of the precise laboratory tests into qualitative field tests, one of which is described in the present communication. For the enzymatic determination, where the reaction temperature is critical, a simple $37^{\circ} \mathrm{C}$ incubator was constructed, which operates from a car battery.

$\gamma$-Glutamyltransferase appears to be a good marker for colostral intake. Braun et al. $(10,11)$, studying the activity of the enzyme in calf serum before and after colostral ingestion, concluded that $\gamma$-glutamyltransferase can serve as a marker for colostral intake. The present study, using the described methodology and conditions, showed somewhat better correlations than those described by Braun et al. $(10,11)$. Boyd (12), devised a computer program which simulated absorption of colostral immunoglobulin and $\gamma$-glutamyltransferase into the blood, andishowed different time courses for the serum concentrations of these two colostrum constituents. Furthermore, the mean times 
required to reach the peak concentrations of the various constituents were different; also, at these peak times, the ratios of the serum concentration to the colostral concentration were different for each constituent. Nevertheless, since the ratio between immunoglobulins and $\gamma$-glutamyltransferase in calf serum remains within a narrow range, the enzyme can be used as an index of colostral intake and absorption.

Our studies also showed a high correlation between $\gamma$-glutamyltransferase and globulins in calf serum, and a lesser correlation between $\gamma$-glutamyltransferase and serum total proteins. Of interest is the high correlation
$(-0.9379)$ between serum $\gamma$-glutamyltransferase and the albumin to globulin ratio. The calculated albumin to globulin ratio is a sensitive quantity which describes the relative distribution of these two proteins in the serum.

The electrophoretic separation of serum and colostrum clearly shows the parallel increases in both $\gamma$ globulin concentrations and $\gamma$-glutamyltransferase activity, thereby rcinforcing the evidence supporting the use of $\gamma$-glutamyltransferase activity as an index of colostral ingestion and of the concentrations of serum $\gamma$-globulins derived from the colostrum.

\section{References}

1. Petrie, L. (1984) Maximizing the absorption of colostral immunoglobulins in the newborn dairy calf. Vet. Rec. 114, 157-163.

2. Stott, G. H., Marx, D. B., Mencttec, B. E. \& Nightengale, G. T. (1979) Colostral immunoglobulin transfer in calves. I. Period of absorption. J. Dairy Sci. 62, 1631-1638.

3. Ishikawa, H. \& Konishi, T. (1982) Changes in serum immunoglobulin levels in suckled calves from birth to five weeks. Vet. Rec. 94, 367-373.

4. Logan, E. F., McBeath, D. G. \& Lowman, B. G. (1974) Quantitative studies on serum immunoglobulin levels in suckled calves from birth to five weeks. Vet. Rec. 94, 367370.

5. Matte, J. J., Girrard, C. L., Seoane, J. R. \& Brisson, G. J. (1982) Absorption of colostral immunoglobulin $G$ in the newborn dairy calf. J. Dairy Sci. 65, 1765-1770.

6. Bush, L. J. \& Staley, T. E. (1980) Absorption of colostral immunoglobulins in newborn calves. J. Dairy Sci. 63, 672680.

7. Stott, G. H., Marx, D. B., Menettee, B. E. \& Nightengale, G. T. (1979) Colostral immunoglobulin transfer in calves. II. The rate of absorption. J. Dairy Sci. 62, 1766-1773.

8. Gay, C. C., McGuire, T. C. \& Parish, S. M. (1983) Seasonal variations in passive transfer of immunoglobulin $\mathrm{G} 1$ to newborn calves. J. Am. Vet. Med. Assoc. 183, 566-568.

9. Nocek, J. E., Brand, D. G. \& Warner, R. G. (1984) Influence of neonatal administration, immunoglobulin and continued feeding of colostrum on calf gain health and serum proteins. J. Dairy Sci. 67, 319-333.

10. Braun, J. P., Bernard, P., Burgat, V. \& Rico, A. G. (1983) Gamma glutamyl transferase in domestic animals. Vet. Rcs. Commun. 6, 77-90.

11. Braun, J. P., Tainturier, D., Laugier, C., Bernard, P., Thouvenot, J. P. \& Rico, A. C. (1982) Early variations of blood plasma gamma glutamyl transferase in newborn calves A test of colostrum intake. J. Dairy Res. 65, 2178-2181.

12. Boyd, J. W. (1987) Computer model of the absorption and distribution of colostral immunoglobulins in newborn calf. Res. Vet. Sci. 43, 291-296.

13. Gornall, A. G., Bardawill, C. J. \& David, D. D. (1949) Determination of serum proteins by means of biuret reaction. J. Biol. Chem. 177, 751-766.

14. Doumas, B. T., Warson, W. A. \& Biggs, H. G. (1971) Albumin standards and the measurement of serum albumin with bromcresol green. Clin. Chom. Acta 31, 87-96.

15. Boehringer-Mannheim GmbH (1989) Reflotron, Manual.

16. Szasz, G. (1976) A kinctic photometric method for gammaglutamyl transpeptidase. Clin. Chem. 15, 124-131.

17. Tietz, N. (ed.) (1986) Fundamentals of Clinical Chemistry. W. B. Saunders Co. Philadelphia, PA.

Prof. Dr. E. Bogin
Kimron Veterinary Institute
and Koret School of
Veterinary Medicine
P. O. Box 12
Bet-Dagan
Israel


• 